\title{
Avaliação do perfil jurisprudencial encontrado no Tribunal Regional do Trabalho da Segunda Região de São Paulo decorrente das alegações de exposição ocupacional do frentista ao benzeno
}

\author{
Rulings of the Regional Labor Court of the Second \\ Region of São Paulo on gas station attendants' \\ occupational exposure to benzene
}

\author{
Giancarlo Rodrigues Brandão ${ }^{1}$ Eduardo Costa Sá2, \\ Márcia Vieira da Motta ${ }^{3}$
}

DOI: http://dx.doi.org/10.11606/issn.2317-2770.v24i2p84-94

\begin{abstract}
Brandão GR, Sá EC, Motta MV. Avaliação do perfil jurisprudencial encontrado no Tribunal Regional do Trabalho da Segunda Região de São Paulo decorrente das alegações de exposição ocupacional do frentista ao benzeno. Saúde, Ética \& Justiça. 2019;24(2):84-94.
\end{abstract}

RESUMO: A exposição ocupacional ao benzeno, substância reconhecidamente cancerígena e hematotóxica, é notória na área siderúrgica, mas pode ocorrer em trabalhadores de empresas que produzem, transportam, armazenam, utilizam ou manipulam derivados de petróleo de maneira geral, como em postos de gasolina. Com a especial atenção à prevenção da sua contaminação pelos frentistas, dada pela Lei Estadual n. 16.656, de 12 de janeiro de 2018, que reforça as normativas sanitárias vigentes de proteção ocupacional dos trabalhadores, buscou-se a frequência com que casos desta natureza chegam aos tribunais trabalhistas e o entendimento dos magistrados ao fundamentar a concessão ou a negativa do direito pleiteado. Nos últimos 18 anos, apenas seis casos de frentistas foram julgados pelo Tribunal Regional do Trabalho da $2^{\mathrm{a}}$ Região por alegada contaminação por benzeno ocupacional. Destes, cinco eram originários de Varas do Trabalho do Litoral Paulista e um da capital. Em apenas um caso não houve perícia, pela impossibilidade de realização de exame presencial, já que o funcionário havia falecido por leucemia. Em outro, foi autorizado novo exame pericial, pois o perito originário desconhecia base científica que relacionasse exposição ocupacional à gasolina com o quadro de leucemia apresentado pelo frentista. Nos demais, as doenças apresentadas foram leucopenia, neutropenia/leucopenia, adenocarcinoma de tiroide e rinite/laringite, tendo sido encontrado nexo entre a exposição e o adoecimento apenas nos dois primeiros casos. No último acórdão encontrado, o frentista buscava somente o reconhecimento da insalubridade do local de trabalho, o que lhe foi negado por prova pericial do posto de combustível. Muito embora poucos casos tenham chegado aos tribunais buscando a responsabilização do empregador em virtude de contaminação ocupacional pelo benzeno em frentistas, a amostra demonstra a importância do histórico de exames médicos periódicos ocupacionais dos funcionários para o esclarecimento da natureza do adoecimento, bem como o conhecimento técnico e científico do perito judicial.

DESCRITORES: Exposição Ocupacional; Benzeno; Indenização aos Trabalhadores.

\footnotetext{
1. Universidade de São Paulo. e-mail: giancarlorbrandao@gmail.com

2. Instituto Médico Legal do Estado de São Paulo.

3. Professora no curso de Especialização em Medicina Legal e Perícias Médicas do Departamento de |Medicina Legal, Ética Médica e Medicina Social e do Trabalho da Faculdade de Medicina da Universidade de São Paulo.

Endereço para correspondência: marcia.motta@gmail.com
} 


\section{INTRODUÇÃO}

$\mathrm{O}$

benzeno é substância cancerígena e hematotóxica, e sua absorção pode ocorrer por via cutânea, digestiva ou respiratória ${ }^{1-8}$. Trata-se de hidrocarboneto aromático, presente na gasolina e em compostos orgânicos, produzido pela indústria petroquímica e química9 Os principais sintomas da sua intoxicação aguda são: sonolência, cefaleias, náuseas, taquicardias, tremores, convulsões, perda de consciência e, em última análise, a morte ${ }^{8,10}$.

Segundo Moura-Correa et al., 2014, o censo de 2010, último nacional realizado pelo $\mathrm{IBGE}^{11}$, indicou que havia no Brasil, 184.733 frentistas, sendo o número de postos de revenda de combustíveis em território nacional, no ano de 2018, 40.021 $1^{12}$. Dados do RAIS (Relação Nacional de Informações Sociais) de 2015 indicam número recente mais elevado, com 261.647 profissionais ${ }^{13,14}$.

A função de frentista no Brasil envolve calibragem de pneus, aferição do nível de óleo, lavagem dos parabrisas, troca de fluídos de freio e de água do radiador, muito embora concentre-se no abastecimento do veículo e sua cobrança. Não raro, esses profissionais exercem também a função de recebimento de combustível para abastecimento do tanque subterrâneo e de limpeza e manutenção das dependências do posto, situações que os deixam especialmente vulneráveis à contaminação pelo benzeno ${ }^{14-17}$, bem como por butadieno, etil benzeno e éter metil-t-butílico ${ }^{18}$, portanto, por substâncias que aumentariam o risco de o profissional desenvolver leucemias e aplasias medulares ${ }^{19}$.
O efeito da exposição excessiva ao benzeno na medula óssea é conhecido há mais de um século, sendo que a exposição em níveis além do permitido no ambiente de trabalho pode ser estudada cumulativamente ao longo dos anos, como nos EUA, ou estabelecida como medida diária como no Brasil.

Estudos colaborativos entre a China e os Estados Unidos indicaram haver efeito dose resposta entre exposição ao benzendo e desenvovimento de leucemia, linfoma, síndrome mieloplástica e anemia aplástica, mesmo em baixas doses ${ }^{20-22}$. Quando se analisa o resultado da exposição cumulativamente, os resultados são os mesmos - aqueles expostos com 15 ppm-anos apresentam significativamente maior adoecimento para leucemia do que os não expostos ${ }^{23,24}$. No Brasil, até a década de 90 , os valores permitidos eram de $8 \mathrm{ppm}^{14}$, ainda quando a exposição ao benzeno colocava a atividade no elenco daquelas classificadas como perigosas e insalubres, para as quais havia adicional compensatório do risco ${ }^{15}$. Hoje, tem-se como o Valor de Referência Tecnológico, ou seja, a concentração média ponderada obtida na zona respiratória para jornada de oito horas, o limite de 2,5 ppm para indústrias siderúrgicas, e 1,0 ppm para outras empresas, como os postos de combustíveis, abrangidos pelo Acordo Nacional do Benzeno ${ }^{26,27}$. É importante lembrar que, mesmo com esses valores, embora não seja consenso nas políticas públicas, já se encontra na literatura associação significativa com pancitopenia, culminando com o aparecimento de anemia aplástica ou leucemia ao longo dos anos ${ }^{19,28,29}$. As principais alterações hematológicas e da medula óssea decorrentes de exposição crônica serão apresentadas na tabela abaixo (Tabela 1)

Tabela 1 - As principais alterações hematológicas oriundas da exposição crônica ao benzeno $0^{6,7,30}$

\begin{tabular}{ll}
\hline Hematológicas \\
\hline Série Vermelha & $\begin{array}{l}\text { anemia, macrocitose, eritroblastose } \\
\text { pontilhados basófilos } \\
\text { policromasia }\end{array}$ \\
\hline Série Branca & $\begin{array}{l}\text { leucopenia, neutropenia, linfocitopenia } \\
\text { leucocitose, neutrofilia, eosinofilia } \\
\text { monocitose, linfocitose }\end{array}$ \\
\hline Série Plaquetária & $\begin{array}{l}\text { trombocitopenia, macroplaquetas } \\
\text { bicitopenia periférica } \\
\text { pancitopenia periférica }\end{array}$ \\
\hline \multicolumn{1}{c}{ Quantitativas } & \multicolumn{1}{c}{ Qualitativas } \\
\hline $\begin{array}{l}\text { Hipo ou hipercelularidade isolada (eritroblástica, granulocítica, } \\
\text { megacariocítica) }\end{array}$ & Setor eritrocitário \\
\hline Hipocelularidade combinada & Setor granulocítico \\
\hline $\begin{array}{l}\text { Hipocelularidade global } \\
\text { Eosinofilia }\end{array}$ & Setor megacariocítico \\
\hline
\end{tabular}


A metabolização do benzeno no organismo ocorre principalmente pelo fígado e, secundariamente, pela medula óssea. Os metabólitos, especialmente o fenol conjugado, mas também a hidroquinona, o ácido trans, transmucônico (AttM) e o ácido S-fenilmercaptúrico, são excretados na urina, sendo que a principal via de eliminação do benzeno não metabolizado, após exposição inalatória, é o ar exalado ${ }^{31,32}$.

Desse modo, não há limite seguro para a exposição ao benzeno, por ser composto comprovadamente genotóxico e cancerígeno, sendo a normatização no Brasil profícua neste sentido desde $1978^{33}$, quando foram aprovadas as Normas Regulamentadoras em Segurança e Saúde no Trabalho (NRs) ${ }^{34}$. O cumprimento dos índices máximos de concentração no local de trabalho é obrigatório, mas não exclui o risco à saúde ${ }^{35}$.

Por meio da Portaria n. 34, de 20 de dezembro de 2001, publicou-se o protocolo para a utilização do indicador biológico para o benzeno, tendo sido adotada a concentração do AttM na urina pós-jornada de trabalho como método eficaz ${ }^{19,36}$. Para agentes químicos, o índice biológico máximo permitido (IBMP) seria aquele em que "o valor máximo do indicador biológico para o qual se supõe que a maioria das pessoas ocupacionalmente expostas não corre risco de dano à saúde. A ultrapassagem desse valor significa exposição excessiva"36. Este indicar biológico não tem significado clínico. Nos EUA, tem-se o valor de $0,5 \mathrm{mg} / \mathrm{g}$ creatinina ${ }^{37}$, reconhecido também pela Portaria DSST n. 34/01 como limite para trabalhadores não ocupacionalmente expostos ao benzeno. A prática da avaliação das concentrações na urina do AttM tem utilizado como referência o limite de detecção do método, ou seja, 0,2 mg/g de creatinina ${ }^{32}$.

Entretanto, o AttM também é metabólito de outras substâncias, como sorbitol e ácido sórbico, o primeiro é um adoçante hoje muito utilizado, e o segundo, substância naturalmente existente em frutas vermelhas, utilizada como aditivo de conservação de alimentos. Assim, tem-se que a dieta pode impactar sensivelmente os resultados urinários, levando a um falso positivo ${ }^{38}$. Por essa razão, desde 1988 a ACGIH (Conferência Americana de Higienistas Industriais) indica o uso de outro biomarcador mais sensível, o ácido fenilmercaptúrico, cujo procedimento de dosagem é mais complexo e oneroso, dificultando seu uso como rotina em países em desenvolvimento ${ }^{31,39}$.

O diagnóstico de intoxicação aguda por benzeno é clínico-laboratorial e epidemiológico. Para ter nexo de causalidade entre trabalho e exposição ocupacional é necessário que haja benzeno no ambiente de trabalho, associado a sinais e sintomas de benzenismo; além disso, devem estar presentes alterações laboratoriais, como macrocitose, linfocitopenia e, principalmente, a neutropenia ${ }^{10,33}$

O estudo da medula óssea não deve ser utilizado de forma isolada, pois a exposição crônica ao benzeno não leva a alterações patognomônicas de benzenismo ${ }^{40}$.

Atualmente, em termos ocupacionais, existe grande impasse para se estabelecer o diagnóstico e a sua vinculação com o trabalho. Pela legislação brasileira, quando se estabelece o nexo de causalidade entre o dano, seja este moral ou material, e a conduta culposa do empregador, fica este obrigado a reparar, ressarcir ou indenizar o funcionário por este dano causado ${ }^{41,42}$, usualmente por meio de litígio nos tribunais federais do trabalho, em que cabe ao perito judicial fornecer ao juízo prova científica para que este possa fundamentar sua sentença.

Para garantir a minimização da exposição, algumas medidas governamentais vêm sendo adotadas, como a Lei n. 16.656 criada pela Assembleia Legislativa do Estado de São Paulo em 2018, que proíbe o enchimento do tanque de combustível além do travamento automático ${ }^{43}$. Igualmente, em nível nacional, assegura-se a proteção da saúde dos funcionários das cerca de 40 mil revendas de combustíveis distribuídas pelo território nacional com a adequação de todas as empresas às normas do anexo II da Norma Regulamentadora (NR) 9, que trata sobre Exposição Ocupacional ao Benzeno em Postos Revendedores de Combustíveis ${ }^{34}$. Esta NR recomenda:

6.2 Os trabalhadores que exerçam suas atividades com risco de exposição ocupacional ao benzeno devem realizar, com frequência mínima semestral, hemograma completo com contagem de plaquetas e reticulócitos, independentemente de outros exames previstos no PCMSO (Programa de controle Médico de Saúde Ocupacional).

6.2.1 Os casos de dispensa de aplicação dos exames previstos no item 6.2 devem ser justificados tecnicamente nos PPRA (Programa de Prevenção de Riscos Ambientais) e PCMSO dos PRC.

6.3 Os resultados dos hemogramas devem ser organizados sob a forma de séries históricas, de fácil compreensão, com vistas a facilitar a detecção precoce de alterações hematológicas.

No intuito de avaliar o entendimento dos tribunais sobre casos envolvendo contaminação por benzeno e o trabalhador frentista, realizou-se levantamento das decisões do Tribunal Regional do Trabalho da $2^{\text {a }}$ região (Estado de São Paulo), buscando a existência de tais lides e o embasamento técnico utilizado para a fundamentação das decisões.

\section{OBJETIVO}

O objetivo deste trabalho foi analisar o perfil dos acórdãos decorrentes da exposição ocupacional dos frentistas ao benzeno, proferidas pelos magistrados do 
Tribunal Regional do Trabalho da Segunda Região (TRT2).

\section{MÉTODO}

Neste estudo foi realizada revisão narrativa ${ }^{44}$ sobre a exposição ocupacional ao benzeno aliada à análise da sua repercussão no $\mathrm{TRT}^{45}$. Os acórdãos foram recuperados por meio do instrumento de busca do tribunal (http://search.trtsp.jus.br/EasySearchFrontEnd/ AcordaosUnificados.jsp), pesquisando-se todos as decisões, as de processos em meio físico ou eletrônico, contendo as palavras "benzeno" e "frentista", no dia 5 de maio de 2019, sem limitação de data. A plataforma disponibiliza digitalmente todos os acórdãos do TRT2 a partir de $8 / 5 / 2001^{46}$. A ementa de cada acórdão foi lida na íntegra para excluir aqueles que tratavam de contaminação em siderúrgicas, com inclusão apenas daqueles em que o reclamante exercia a função de frentista e alegava prejuízo em decorrência da exposição ocupacional ao benzeno.

Os resultados obtidos foram organizados e apresentados na Tabela II, segundo: a) número do processo, b) utilização do laudo médico pericial para embasamento da decisão judicial, c) estabelecimento de nexo causal ou de concausa, e d) indenização. Na sequência, apresentou-se resumo e discussão do conteúdo de cada acórdão.

\section{RESULTADOS}

Inicialmente foram recuperadas 48 decisões, reduzidas a sete aplicando-se os critérios de inclusão e exclusão ${ }^{33-39}$. Destas, seis eram originários de varas do trabalho (VT) do litoral sul de São Paulo; apenas uma apresentou origem na capital paulista ${ }^{51}$. Em três decisões ${ }^{48,50,52}$, determinou-se o nexo causal entre a exposição ocupacional ao benzeno e o trabalho de frentista, mas em apenas dois foram as rés condenadas a indenizar os funcionários pelos danos causados. $\mathrm{O}$ nexo causal foi estabelecido pela perícia em outra decisão, porém houve discordância dos magistrados com o achado, e não foi reconhecido o dever de indenização, tendo em vista a negativa do nexo pela Previdência Social e não ter havido regressão da patologia, rinite/laringite, mesmo cinco anos após seu afastamento ${ }^{50}$. Em um processo, o da $20^{\mathrm{a}}$ VT de São Paulo ${ }^{51}$, não houve conclusão do caso, pois o processo retornou à vara de origem para realização de nova perícia, por falta de conhecimento específico do perito originário.

O valor das indenizações pagas pelas empresas condenadas em relação à contaminação pelo Benzeno variou entre 10 e 20 mil reais. Os resultados obtidos foram agrupados na Tabela 2. Os Acórdãos foram discutidos individualmente, tendo em vista a complexidade de cada caso.

Tabela 2 - Decisões de $2^{\mathrm{a}}$ instância do TRT2 envolvendo frentistas de postos de abastecimento de gasolina e exposição ocupacional ao benzeno (2001-2019)

\begin{tabular}{|c|c|c|c|c|c|}
\hline Acórdão & $\begin{array}{c}\text { Vara de } \\
\text { origem (VT) }\end{array}$ & TRT2 & $\begin{array}{l}\text { Laudo pericial utilizado } \\
\text { pelos magistrados na } \\
\text { sentença (origem) }\end{array}$ & $\begin{array}{l}\text { Nexo Causal ou } \\
\text { Concausa }\end{array}$ & Indenização (Valor) \\
\hline $1^{47}$ & $\begin{array}{l}2^{\mathrm{a}} \mathrm{VT} \text { de } \\
\text { Santos }\end{array}$ & $\begin{array}{c}1^{\mathrm{a}} \\
\text { turma }\end{array}$ & Não existiu perícia & Não & - \\
\hline $2^{48}$ & $\begin{array}{l}2^{\mathrm{a}} \text { VT de São } \\
\text { Vicente }\end{array}$ & $\begin{array}{c}7^{\mathrm{a}} \\
\text { turma }\end{array}$ & Sim & Sim & $\mathrm{R} \$ 20.000,00$ \\
\hline $3^{49}$ & $\begin{array}{l}4^{\mathrm{a}} \mathrm{VT} \text { de } \\
\text { Santos }\end{array}$ & $\begin{array}{c}14^{\mathrm{a}} \\
\text { turma }\end{array}$ & Sim & Não & - \\
\hline $4^{50}$ & $\begin{array}{l}2^{\mathrm{a}} \text { VT de São } \\
\text { Vicente }\end{array}$ & $\begin{array}{c}9^{\mathrm{a}} \\
\text { turma }\end{array}$ & Desconsiderou o laudo & $\begin{array}{l}\text { Sim } \\
\text { (estabelecido } \\
\text { pelo perito) }\end{array}$ & - \\
\hline $5^{51}$ & $\begin{array}{l}20^{\mathrm{a}} \text { VT de São } \\
\text { Paulo }\end{array}$ & $\begin{array}{c}14^{\mathrm{a}} \\
\text { turma }\end{array}$ & \multicolumn{3}{|c|}{$\begin{array}{c}\text { Observação: retorno dos autos à vara de origem para realização de nova } \\
\text { perícia. }\end{array}$} \\
\hline $6^{52}$ & $\begin{array}{l}2^{\mathrm{a}} \mathrm{VT} \text { de } \\
\text { Guarujá }\end{array}$ & $\begin{array}{c}11^{\mathrm{a}} \\
\text { turma }\end{array}$ & \multicolumn{2}{|l|}{ Sim } & $\mathrm{R} \$ 10.000,00$ \\
\hline $7^{53}$ & $\begin{array}{c}1^{\text {a }} \text { VT de Praia } \\
\text { Grande }\end{array}$ & $\begin{array}{c}15^{\mathrm{a}} \\
\text { turma }\end{array}$ & \multicolumn{2}{|l|}{ Sim } & $\begin{array}{l}\text { Observação: perícia } \\
\text { associada à vistoria do local } \\
\text { de trabalho para determinar } \\
\text { pagamento de insalubridade. }\end{array}$ \\
\hline
\end{tabular}


Brandão GR et al. Avaliação do perfil jurisprudencial encontrado no Tribunal Regional do Trabalho da Segunda Região.

\section{DISCUSSÃO}

No primeiro acórdão, trata-se de caso de frentista morto por leucemia linfoide aguda, que supostamente devida à exposição ao benzeno. Relata sua ementa ${ }^{47}$ :

ACORDAM os Magistrados da $1^{\text {a }}$ Turma do Tribunal Regional do Trabalho da $2^{\text {a }}$ Região em: DAR PROVIMENTO ao recurso para excluir da condenação o pagamento de indenizações por dano moral, lucros cessantes e emergentes, e julgar improcedente a reclamatória, com custas em reversão, na forma da lei, das quais fica a reclamante isenta, por beneficiária da justiça gratuita.

O processo apresenta origem na VT de Santos. A perícia não foi realizada, mesmo que indiretamente nos documentos, pois os magistrados concluíram ser impossível o estabelecimento do nexo por esta via, inclusive por não ter sido estabelecido o nexo pelo INSS (Instituto Nacional do Seguro Social). Por isso, o pedido de indenização foi julgado improcedente.

Por primeiro que a reclamada pretendeu, em contestação (fls. 684), a realização de perícia médica, sem atentar que o ex-empregado é falecido o que, por óbvio, torna impossível a realização da prova pretendida. (grifa-se)

Dada a comprovada relação, estabelecida na literatura, entre a exposição ocupacional ao benzeno e a leucemia ${ }^{19}$, e o fato de a patologia apresentada estar mais relacionada à infância ${ }^{54}$ e ser rapidamente progressiva ${ }^{55}$, caberia à análise pericial documental, por exemplo, examinar a cronologia da alteração hematológica dos exames periódicos ocupacionais, estabelecer ou afastar o nexo, ou mesmo determinar a impossibilidade de sua realização, garantindo ao trabalhador, decisão mais científica, técnica e justa.

$\mathrm{O}$ acórdão seguinte trouxe caso em que o perito judicial estabeleceu nexo causal, reconhecido pelos magistrados, entre a leucopenia do frentista e a exposição ocupacional ao benzeno, concorrendo com a conduta injuriosa o fato de a empresa ter omitido os exames ocupacionais do funcionário ${ }^{48}$.

Também, consoante laudo e esclarecimentos (fls. 142/151 e 185/187), o Perito do Juízo atestou o nexo de causalidade entre o quadro de saúde apresentado e o trabalho desenvolvido pelo recorrido (reclamante). [...] “...empregado, por não ter acesso aos exames periódicos realizados durante o vínculo empregatício, desconhecia seu real estado de saúde. E desconhecia porque a reclamada nunca the apresentou os resultados, o que somente foi efetuado após a propositura da ação cautelar de exibição de documentos... está claro que a atitude do empregador, ao sonegar informações de extrema relevância à saúde do trabalhador, causou dano de grande monta, impedindo-o de realizar tratamento adequado no início da doença. E além de omitir tais informações, manteve o reclamante nas mesmas funções, o que... deve ter contribuído para ao agravamento da doença." ${ }^{43}$

A legislação trabalhista, no ano de $1978^{34}$, implementou as chamadas NRs e, entre elas, a NR 7, que estabelece regras para o controle médico ocupacional:

[...] estabelece a obrigatoriedade de elaboração e implementação, por parte de todos os empregadores e instituições que admitam trabalhadores como empregados, do Programa de Controle Médico de Saúde Ocupacional (PCMSO).

O PCMSO apresenta como objetivo a promoção e preservação da saúde do conjunto dos trabalhadores e inclui, entre outras atribuições, a realização obrigatória dos exames médicos periódicos (EMPs). Tais exames são compostos de: avaliação clínica e exames complementares, realizados de acordo com os termos específicos da NR e seus anexos. A periodicidade está relacionada com a atividade desenvolvida e com o risco ocupacional a que os trabalhadores estão submetidos, além de com a idade. A prática dos EMPs é intrinsicamente vinculada à Saúde Ocupacional, demonstrando a importância do funcionário ter acesso ao seu conteúdo, principalmente em funções com maior risco ocupacional ${ }^{56}$.

Na terceira decisão analisada, a perícia confirmou que o frentista que alegava ter um carcinoma na garganta em razão à exposição ao benzeno apresentava, na verdade, um adenocarcinoma papilífero de tireoide, que não teria relação com exposição ocupacional ao benzeno. A decisão em segunda instância manteve inalterada a sentença de origem, negando provimento ao recurso do funcionário ${ }^{49}$.

De fato, o carcinoma papilífero é uma neoplasia maligna tireoidiana comum, sendo sua relação com a exposição à radiação ionizante conhecida de longa data, estando possivelmente também associada à tireoidite de Hashimoto, causa mais frequente de hipotireoidismo em áreas onde os níveis de iodo são adequados ${ }^{57,58}$. Por ser reconhecidamente carcinogênico, não é possível excluir que sua etiologia possa estar relacionada ao benzeno, havendo literatura que corrobora a relação à longas exposições ao hidrocarboneto ${ }^{59,60}$, muito embora não se reconheça a relação causal de poluentes ambientais com câncer de tireoide em humanos ${ }^{61}$.

Em decisão com origem em São Vicente, a quarta analisada, o juízo indeferiu o pedido de indenização da frentista, em que a perícia reconheceu o nexo de causalidade entre a doença, rinite/laringite, e sua atividade profissional ${ }^{50}$. Em segunda instância, foram considerados na decisão o fato de o INSS não 
ter estabelecido nexo de causalidade entre a doença e a função de frentista e o fato de que, mesmo afastada por quase cinco anos, a funcionária não havia apresentado remissão dos sintomas.

É importante esclarecer a dificuldade pericial em se estabelecer o nexo causal da rinite de cunho ocupacional, não existindo definição consensual do que seria rinite ocupacional. Seus sintomas podem surgir devido a alérgenos ocupacionais presentes no ambiente de trabalho, como poeira de trigo, poeira de madeira e de produtos detergentes ${ }^{62}$. Diferentemente da asma ocupacional que, além de ser mais documentada, é "doença respiratória associada ao trabalho com maior prevalência em países desenvolvidos" $" 63,64$.

Para demonstrar a etiologia da rinite ocupacional tem-se usado a prova de provocação nasal específica (PPNE) de forma não padronizada, utilizando seus escores na confirmação ou exclusão do diagnóstico. Trata-se de prova positiva quando algum agente presente no ambiente de trabalho sensibiliza o teste, ou seja, atinge escores suficientemente positivo após excluir outras causas de rinite ${ }^{62,65}$. Esta prova pode ser realizada em ambiente controlado, mas, preferencialmente, deve ser executada em ambiente de trabalho. Os sintomas estão presentes nos dias de trabalho e melhoram nos feriados e finais de semana ${ }^{62}$. No caso específico, a decisão judicial é corroborada pela literatura, que não considera casos persistentes, como o da frentista, relacionados ao trabalho.

$\mathrm{Na}$ sequência, a quinta decisão da amostra reconheceu a improficiência do perito de primeira instância que afirmou desconhecer trabalhos que relacionassem o surgimento de Leucemia Mieloide Crônica à exposição ocupacional de frentista. Neste caso, foi determinada realização de nova perícia ${ }^{51}$ :

Ouso discordar do perito. Ele próprio afirma que o reclamante abastecia veículos. Se assim procedia, por óbvio estava exposto ao forte odor que qualquer pessoa sente ao chegar perto de um posto de combustíveis. Por ser matéria de cartilha de vestibular, me permito fazer uma breve descrição do porquê deste cheiro. A gasolina é composta de uma série de hidrocarbonetos, moléculas cuja estrutura é formada por átomos de hidrogênio e carbono e que são extremamente voláteis - possuem enorme facilidade de passar do estado físico líquido para o gasoso -, daí serem facilmente inaláveis, o que explica o forte cheiro nos postos de combustíveis. Uma dessas substâncias, encontrada na gasolina, é justamente o benzeno. Se o autor era frentista, abastecia veículos e lidava frequentemente com gasolina, que possui benzeno em sua composição, sendo este extremamente volátil, como que o reclamante poderia não inalar (ter contato pelas vias respiratórias) tal substância $?^{51}$ (grifa-se)

Ademais, o perito demonstrou estar totalmente desavisado do tema, pois alegou, à fl. 142, desconhecer totalmente qualquer trabalho científico que relacione o surgimento da doença da qual sofre o autor com o trabalho de pessoas que lidam com

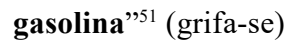

É de se destacar que órgãos internacionais, como IARC (International Agency for Research on Cancer), da Organização Mundial de Saúde; a americana ACGIH, e o Parlamento Europeu, dizem justamente o contrário, que o benzeno é sabidamente carcinogênico ${ }^{2-4,66}$. Tal reconhecimento reflete-se amplamente na legislação brasileira, com a edição de normas que visam a controlar esse solvente no ambiente de trabalho, obrigando as empresas a cumprir com as exigências normativas e legais, tais quais a NR $9^{34}$ e a Lei n. 16.656 do Estado de São Paulo ${ }^{43}$. Portanto, os magistrados determinaram o retorno dos autos para a vara de origem $\left(20^{\mathrm{a}} \mathrm{VT}\right.$ de São Paulo) para produção de nova prova pericial, desta vez, com perito judicial com capacitação técnica para esclarecer o caso.

$\mathrm{Na}$ sexta decisão estudada, em caso da VT de Guarujá ${ }^{52}$, reconheceu o tribunal o nexo causal estabelecido em primeira instância entre a função de caixa de posto com trabalho eventual de frentista, e a neutropenia e leucopenia apresentada pelo trabalhador, em razão da exposição ao benzeno.

Atestou o Sr. Perito a "diminuição de capacidade laborativa em quantidade, qualidade e principalmente competitividade de trabalho, consignado que a reclamante: Apresenta condições de exercer funções compatíveis com a sua condição, porém não aquelas anteriormente exercidas, onde ocorra exposição inalatória de produtos."

A patologia ocupacional (dano) da reclamante é fato (ato) inequívoco e decorreu de nexo causal com sua função e por atividade laboral sem a observância das regras de proteção e medicina do trabalho, por culpa do empregador (agente), passível, pois, de gerar indenização por dano moral, porquanto quem causa dano a alguém se obriga a uma reparação, é a responsabilidade civil $^{52}$.

O nexo, neste caso, foi estabelecido apenas pela constatação da neutropenia e leucopenia, alterações que podem ocorrer de forma inespecífica, não relacionada ao trabalho.

É importante destacar que para se relacionar o adoecimento do funcionário com exposição ocupacional ao benzeno, o seguinte tripé deve-se fazer presente: sintomatologia de benzenismo, comprovação do benzeno fora dos padrões no ambiente de trabalho e alterações laboratoriais ${ }^{31}$. Assim, a comprovação de nexo apenas com resultados genéricos, que podem ser atribuídos a inúmeras patologias, se faz temerosa, 
trazendo grande insegurança para o empregador. A Portaria $34 / 01^{36}$ descreve o cuidado que se deve tomar no estabelecimento no nexo causal ocupacional, afastando outras possíveis causas do adoecimento, já que falsos positivos podem ocorrer mesmo com as melhores práticas sugeridas no protocolo, sendo de grande importância a correlação dos dados laboratoriais com a concentração de benzeno no ar.

No último acórdão estudado ${ }^{53}$, o sétimo da amostra, não houve adoecimento do autor, que acumulava as funções de caixa e frentista, mas sim pleito por insalubridade por possível exposição ao benzeno. A perícia descartou a insalubridade uma vez que o indivíduo "somente realizava a colocação e remoção da bomba de abastecimento". Decidiram os magistrados, que a "ausência de contato com o combustível por parte do trabalhador retira-lhe o direito ao adicional de insalubridade".

De acordo com o art. 195 da Consolidação das Leis Trabalhistas (CLT), a caracterização e classificação da insalubridade e periculosidade devem ser realizadas por meio de perícia do estabelecimento ou setor, seguindo as normas do ministério do trabalho, a cargo do médico do trabalho ou engenheiro do trabalho ${ }^{67}$. Todavia, o benzeno foi excluído pela Portaria SSST n. 3 , de 10 de março de $1994^{68}$ da tabela de limites de tolerância de agentes químicos, sendo determinado que "não deve ser permitida exposição ou contato" ao benzeno ${ }^{34}$

Nenhuma exposição ou contato significa hermetizar o processo ou operação, através dos melhores métodos praticáveis de engenharia, sendo que o trabalhador deve ser protegido adequadamente de modo a não permitir nenhum contato com o carcinogênico. Sempre que os processos ou operações que envolvem as 5 (cinco) substâncias citadas não forem hermetizados, será considerado como situação de risco grave e iminente para o trabalhador, além de insalubridade de grau máximo ${ }^{68}$.

Assim, tecnicamente acertada a decisão. Vale ressaltar, a maioria dos acórdãos, ou seja, seis dos sete acórdãos recuperados tiveram origem no litoral sul de São Paulo, região com siderúrgicas, cujos processos de natureza trabalhista costumam abordar o benzenismo, indicando, talvez, um conhecimento mais especializado dos advogados da área. Os dados processuais não permitiram que se recuperasse o local em que os trabalhadores viviam no litoral paulista, já que como as cidades são muito próximas, poderiam todos residir em uma mesma região, reforçando a origem ambiental do adoecimento. Deste modo, seria interessante que mais estudos fossem realizados determinando a contaminação ambiental da região, e um acompanhamento técnico mais próximo por parte dos médicos do trabalho desses frentistas, ressaltando que o presente estudo compreendeu todas as demandas decididas pelo TRT2 até maio de 2019.

\section{CONCLUSÃO}

O presente estudo analisou as decisões de recursos apresentados ao Tribunal Federal do Trabalho da $2^{\text {a }}$ Região, de casos em que o trabalhador, com função de frentista, alegava problemas de saúde relacionados à exposição ocupacional ao benzeno.

Os resultados demonstram haver poucos litígios no Estado de São Paulo, apenas sete até o ano de 2019, dos quais seis eram originários de VT do litoral sul paulista. As alegadas doenças ocupacionais foram: leucopenia, neutropenia, leucemia linfoide aguda, leucemia mieloide crônica, adenocarcinoma de tiroide e rinite/laringite. Houve nexo estabelecido nos dois primeiros casos apenas.

$\mathrm{Na}$ decisão sobre leucemia linfoide aguda, entenderam os magistrados que seria impossível a perícia, pois o trabalhador já havia falecido. Já no caso de leucemia mieloide crônica, entenderam que a perícia realizada havia sido ineficiente e precisaria ser refeita, pois não considerou o nexo por supostamente inexistirem trabalhos científicos que corroborassem a relação benzeno/alterações sanguíneas. Nas demais, o nexo foi afastado após realização de perícia, o primeiro, também, por não reconhecer o perito que a literatura relacionasse câncer de tireoide com exposição ao benzeno, e o segundo, pelo trabalhador estar afastado há 5 anos do trabalho e os sintomas da rinite persistirem.

Em um único caso não houve adoecimento do trabalhador, mas, sim, busca por decisão judicial que lhe garantisse o adicional por insalubridade pela exposição ao benzeno, afastada pela ilegalidade do pedido e comprovação de que o empregador seguia as normas de proteção ao trabalhador e não havia contato deste com o combustível.

Embora composto por esta pequena amostra, o trabalho demonstrou a importância da capacitação do perito para a análise criteriosa do estabelecimento do nexo em casos como estes, e da análise da série histórica de exames periódicos ocupacionais para corroborar ou afastar o nexo entre a exposição ao benzeno e o adoecimento do trabalhador. 
Brandão GR, Sá EC, Motta MV. Rulings of the Regional Labor Court of the Second Region of São Paulo on gas station attendants' occupational exposure to benzene. Saúde, Ética \& Justiça. 2019;24(2):84-94.

\begin{abstract}
Occupational exposure to benzene, a known carcinogenic and haematotoxic substance, is well-known in the steel industry, but might also occur in workplaces where petroleum products are produced, transported, stored, used or manipulated, such as gas stations. São Paulo State Law No. 16.656, of January 12, 2018 establishes preventive measures against the contamination of gas station workers, reinforcing the current occupational safety regulations. This paper aimed to verify how often cases of this nature reached the labor courts, as well as the judges' reasoning when granting or denying the right being claimed. In the last 18 years, only six such cases have reached the Regional Labor Court of the second region (State of São Paulo) for alleged occupational benzene contamination. Of these, five came from Labor Courts of the coast of São Paulo and one from the capital. The court did not request expert opinion in only one case, as they considered it was impossible to conduct face-to-face examination given the employee had died of leukemia. In one case, additional expert opinion was solicited by the Court of Appeal, since the original expert claimed not knowing any scientific basis relating occupational gasoline exposure and the leukemia presented by the gas station attendant. In the other cases, the diseases presented were leukopenia, neutropenia/leukopenia, thyroid adenocarcinoma and rhinitis/laryngitis; a direct causal relation between occupational benzene exposure and the employee's illness was found only in the first two cases. In the last decision, the gas station attendant sought the court only to recognize the unhealthy conditions of the workplace; the expert evidence concluded otherwise. Few cases have reached the courts in recent years seeking employer liability in cases of occupational benzene contamination in gas station attendants. Despite the small sample, this research indicates the importance of the occupational medical record of the employee, with their regular examinations, to clarify the nature of the occupational illness. It also shows the importance of the expert's technical and scientific knowledge to help judges reach a decisions.
\end{abstract}

KEY WORDS: Occupational Exposure; Benzene; Workers Compensation.

\section{REFERÊNCIAS}

1. US Department of Health and Human Services. Agency of Toxic Substances and Disease Registry. Benzene [Internet]. Atlanta; 2011 [Acesso em 2019 jul. 15]. Diponível em: https://www.atsdr.cdc.gov/substances/ toxsubstance.asp?toxid $=14$

2. American Conference of Governamental and Industrial Hygienists (ACGIH). Guide for evaluation and control of workplace exposure to chemical substances and physical agents (TLVs) and Biological Exposure Indices (BEIs). Cincinnati: ACGHI Signature Publications, 2019. p. 272.

3. Comissão Europeia. A Comissão propõe valores-limite para o benzeno e o monóxido de carbono IP/98/1049 [Internet]. Bruxelas; 1998 [Acesso em 2019 jul. 15]. Diponível em: https://europa.eu/rapid/press-release_IP98-1049 pt.htm

4. The Internation Agency for Research on Cancer. Working Group on the Evaluation of Carcinogenic Risks to Humans. Benzene. In: IARC Working Group on the Evaluation of Carcinogenic Risks to Humans. A review of human carcinogens. Part F: Chemical agents and related occupations. $1^{\text {st }}$ ed. Lyon, France: IARC; 2012. p. 249-94.

5. Moura-Correa MJ, Jacobina AJR, dos Santos SA, Pinheiro RDC, Menezes MAC, Tavares AM, Pinto NF. Exposição ao benzeno em postos de revenda de combustíveis no Brasil: Rede de Vigilância em Saúde do Trabalho (VISAT). Ciênc Saúde Coletiva [Internet]. 2014 [Acesso em 2019 jul. 15];19(12):463748. Disponível em: https://www.scielo.br/scielo. php?pid=S1413-81232014001204637\&script $=$ sci abstract\&tlng=pt. DOI: https://doi.org/10.1590/1413812320141912.12772014

6. Ruiz MA. Correlação de estudo citológico de histológico de medula óssea em pacientes neutroênicos oriundos de uma indústria siderúrgica de Cubatão. Bol Soc Bras Hematol Hemat. 1988;10:84.

7. Ruiz MA. Alterações hematológicas do benzenismo. Bol Soc Bras Hematol Hemat. 1987;9:129-34.

8. Ruppenthal JE. Toxicologia. $1^{\text {a }}$ ed. Santa Maria: Colégio Técnico Industrial de Santa Maria; 2013.

9. Weisel CP. Benzene exposure: and overview of monitoring methods and their findings. Chem Biol Interact. 2010;184(1-2):58-66. DOI: https://doi.org/10.1016/j. cbi.2009.12.030

10. Arcuri ASA, Costa DF, Possebon J, Kanasawa KC, Tardini LIN, Constantino L, et al. Efeitos da exposição ao benzeno para a saúde. $1^{\text {a }}$ ed. São Paulo: Fundacentro; 2012.

11. Instituto Brasileiro de Geografia e Estatística. Censo Demográfico Brasileiro de 2010. Rio de Janeiro: IBGE; 2011.

12. Agência Nacional do Petróleo, Gás Natural e Biocombustíveis. Anuário estatístico brasileiro do petróleo, gás natural e biocombustíveis 2019 - Seção 3: Comercialização [Internet]. Rio de Janeiro; 2019 [Acesso em 2019 jul. 15]. Diponível em: http://www.anp.gov. br/component/content/article/2-uncategorised/5258anuario-estatistico-2019-dados-abertos\#secao3

13. Comitê de Estatísticas Sociais. Base de dados da relação 
Brandão GR et al. Avaliação do perfil jurisprudencial encontrado no Tribunal Regional do Trabalho da Segunda Região.

anual de informações sociais [Internet]. Brasília; 2018 [Acesso em 2019 jul. 15]. Diponível em: https://ces.ibge. gov.br/base-de-dados/metadados/mte.html.

14. Campos AG. Análise da atividade do frentista diante do perigo da exposição ao benzeno [dissertação]. Recife: Fundação Oswaldo Cruz. Instituto Aggeu Magalhães; 2017.

15. Ceccon JJ. Qualidade no atendimento dos postos de combustíveis da Grande Vitória [Internet]. Vitória; 2008 [Acesso em 2019 jul. 15]. Diponível em: http://craes. org.br/2018/arquivos/artigos/ARTIGO_QUALIDADE_ NO_ATENDIMENTO_DOS_POSTOS_DE

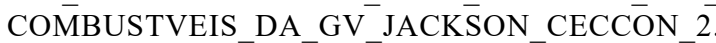
pdf

16. D'Alascio RG, Menegali M, Bornelli AS, Magajewski F. Sintomas relacionados à exposição ocupacional ao benzeno e hábitos ocupacionais em trabalhadores de postos de revenda de combustíveis a varejo na região sul de Santa Catarina. Rev Bras Med Trab. 2014;12(1):21-9.

17. Ferreira MC, Freire ON. Carga horária e rotatividade na função de frentista. Rev Adm Contemp. 2001;5(2):175-200. DOI: https://doi.org/10.1590/S141565552001000200009

18. Keena JJ, Gaffney SH, Galbraith DA, Beatty P, Paustenbach DJ. Gasoline: a complex chemical mixture, or a dangerous vehicle for benzene exposure? Chem Biol Interact. 2010;184(1-2):293-5. DOI: https:// doi.org/10.1016/j.cbi.2010.01.016

19. US Department of Health and Human Services. Agency for Toxic Substances and Disease Registry. Toxicological Profile for Benzene. 3. Health Effects [Internet]. Atlanta; 2007 [Acesso em 2019 jul. 15]. Diponível em: https:// www.atsdr.cdc.gov/toxprofiles/tp3-c3.pdf

20. Hayes RB, Yin SN, Dosemeci, M, Li GL, Wacholder $\mathrm{S}$, Chow $\mathrm{WH}$, et al. Mortality among benzeneexposed workers in China. Environ Health Perspect. 1996;104(S6):1349-52. DOI: https://doi.org/10.1289/ ehp. 961041349

21. Hayes RB, Dosemeci M, Wacholder S, Travis LB, RothmanN, Hoover RN, et al. Benzene and the DoseRelated Incidence of Hematologic Neoplasms in China. JNCI: Journal of the National Cancer Institute. 1997;89(14):1065-71. DOI: https://doi.org/10.1093/ jnci/89.14.1065

22. Dosemeci M, Yin SN, Linet M, Wacholder S, Rothman $\mathrm{N}$, Li GL, et al. Indirect validation of benzene exposure assessment by association with benzene poisoning. Environmental health perspectives. Environ Health Perspect. 1996;104(S6):1343-7. DOI: https://doi. org/10.1289/ehp.961041343

23. Wong O. An industry wide mortality study of chemical workers occupationally exposed to benzene. I. General results. Br J Ind Med. 1987a;44(6):365-81. DOI: https:// doi.org/10.1136/oem.44.6.365

24. Wong O. An industry wide mortality study of chemical workers occupationally exposed to benzene. II. Dose response analysis. Brit J Ind Med. 1987b;44(6):382-95. DOI: https://doi.org/10.1136/oem.44.6.382
25. Brasil. Ministério do Trabalho, Indústria e Comércio. Portaria Ministerial SCm n ${ }^{\circ}$ 51, de 13 de abril de 1939. Diário Oficial da União. 1939 abr. 17; Seção 1. p. 32-45.

26. Confederação Nacional da Indústria. Acordo Nacional do Benzeno. In: Confederação Nacional da Indústria. Consolidação da legislação sobre o benzeno. $1^{\text {a }}$ ed. Brasília, DF: CNI/SESI; 2012. p. 19-35.

27. Brasil. Ministério do Trabalho. Portaria $\mathrm{n}^{\circ} 14$, de 20 de dezembro de 1995. Altera a redação do item "Substâncias Cancerígenas" do Anexo XIII da Norma Regulamentadora NR-15 - Atividades e Operações Insalubres - e inclui o Anexo XIII-A "Benzeno". Diário Oficial da União. 1995 dez. 22; Seção 1. p. 21865-6.

28. Snyder R. Leukemia and Benzene. Int J Environ Res Public Health. 2012;9(8):2875-93. DOI: https://doi. org/10.3390/ijerph9082875

29. Dear JA. Standard Interpretations: 8-hour total weight average (TWA) permissible exposure limit (PEL) [Internet].Washington D.C.; 1995. [Acesso em 2019 jul. 15]. Diponível em: https://www.osha.gov/laws-regs/ standardinterpretations/1995-10-06-3

30. Ruiz MA. Resultado histológico da medula óssea (BMO) de 135 pacientes de um serviço de medicina ocupacional. Bol Soc Bras Hematol Hemat. 1990;12:81.

31. Verrastro T, Mendes R. Sangue e órgãos formadores. In: Mendes R. Patologia do Trabalho. $1^{\mathrm{a}}$ ed. São Paulo: Atheneu; 1995. p. 229-52.

32. dos Santos MVC, Figueiredo VO, Arcuri ASA, CostaAmaral IC, Gonçalves ES, Larentis AL. Aspectos toxicológicos do benzeno, biomarcadores de exposição e conflitos de interesses. Rev Bras Saúde Ocup. 2017;42(1):1-6. DOI: https://doi.org/10.1590/23176369nota00017

33. Arcuri ASA, Cardoso LMN. Acordo e legislação sobre o benzeno: 10 anos. $1^{\text {a }}$ ed. São Paulo: Fundacentro; 2005.

34. Brasil. Ministério do Trabalho. Portaria $\mathrm{n}^{\circ} 3.214$, de 8 de junho de 1978. Aprova as Normas Regulamentadoras - NR - do Capítulo V, Título II, da Consolidação das Leis do Trabalho, relativas à Seguranca e Medicina do Trabalho. Diário Oficial da União. 1978 jul. 06; Seção 1. p. $65-160$.

35. Mendes M, Machado JMH, Durand A, CostaAmaral IC, Valente D, Gonçalves ES, et al. Normas ocupacionais do benzeno: uma abordagem sobre risco e exposição nos postos de revenda de combustíveis. Rev Bras Saúde Ocup [Internet]. 2017 [Acesso em 2019 jul. 15];42(S1):e3s. Disponível em: http://www. scielo.br/scielo.php?script=sci_arttext\&pid=S030376572017001000303\&lng=en. DOI: http://dx.doi. org/10.1590/2317-6369000127515

36. Brasil. Secretaria de Inspeção do Trabalho/Departamento de Segurança e Saúde no Trabalho. Portaria MTE $\mathrm{n}^{\mathrm{o}}$ 34, de 20 de Dezebro de 2001. Publica protocolo visando determinar os procedimentos para a utilização de indicador biológico de exposição ocupacional ao benzeno. Diário Oficial da União. 2001 dez. 27; Seção 1. p. $260-72$.

37. American Conference of Governamental Industrial 
Brandão GR et al. Avaliação do perfil jurisprudencial encontrado no Tribunal Regional do Trabalho da Segunda Região.

Hygienists. Threshold limit values for chemical substances and physical agents. Biological exposures indices. $7^{\text {th }}$ ed. Cincinatti: ACGIH; 2002.

38. Buschinelli JT. Manual de orientação sobre controle médico ocupacional da exposição a substâncias químicas. $1^{\mathrm{a}}$ ed. São Paulo: Fundacentro; 2014.

39. Martins I, Siqueira MEPB. Trans,trans-muconic acid in urine samples collected in three periods from benzene handling workers in a Brazilian refinery. Rev Bras Cienc Farm [Internet]. 2004 [Acesso em 2019 jul. 15];40(2):197-201. Disponível em: http://www. scielo.br/scielo.php?script $=$ sci_arttext\&pid $=\mathrm{S} 1516$ 93322004000200008\&lng=en. DOI: http://dx.doi. org/10.1590/S1516-93322004000200008

40. Ruiz MA, Vassalo J, Souza, CA. Alterações hematológicas de pacientes expostos cronicamente ao benzeno. Rev Saúde Pública [Internet]. 1993 [Acesso em 2019 jul. 15]; 27(2):145-51. Disponível em: http://www. scielo.br/scielo.php?script=sci arttext\&pid $=\mathrm{S} 0034$ 89101993000200011\&lng=en. $\quad$ DOI: https://doi. org/10.1590/S0034-89101993000200011

41. Brasil. Presidência da República, Casa Civil, Subchefia para Assuntos Jurídicos. Lei $\mathrm{n}^{\circ}$ 10.406, de 10 de janeiro de 2002. Institui o Código Civil [Internet]. Brasília, DF; 2002. [Acesso em 2019 jul. 15]. Diponível em: http:// www.planalto.gov.br/ccivil_03/leis/2002/110406.htm

42. Brasil. Presidência da República, Casa Civil, Subchefia para Assuntos Jurídicos. Constituição da República Federativa do Brasil de 1988 [Internet]. Brasília, DF; 1988. [Acesso em 2019 jul. 15]. Diponível em: http://www.planalto.gov.br/ccivil_03/Constituicao/ ConstituicaoCompilado.htm

43. São Paulo. Assembleia Legislativa do Estado de São Paulo. Lei no 16.656, de 12 de janeiro de 2018. Pró́be que postos de combustíveis abasteçam com combustível os veículos após acionada a trava de segurança da bomba de abastecimento [Internet]. São Paulo, SP; 2018. [Acesso em 2019 jul. 15]. Diponível em: https://www.al.sp.gov. br/repositorio/legislacao/lei/2018/lei-16656-12.01.2018. html

44. Rother ET. Revisão sistemática x revisão narrativa. Acta Paul Enferm [Internet]. 2007 [Acesso em 2019 jul. 15];20(2):V-VI. Disponível em: http://www. scielo.br/scielo.php?script=sci_arttext\&pid=S010321002007000200001\&lng=en. DOI: https://doi. org/10.1590/S0103-21002007000200001

45. São Paulo. Tribunal Regional do Trabalho da $2^{\text {a }}$ Região. Pesquisa de acórdãos [base de dados online]. São Paulo: TRT2. 2019 [acesso em 2019 jul. 15]. Diponível em: http://search.trtsp.jus.br/EasySearchFrontEnd/ AcordaosUnificados.jsp

46. Melo D. Banco de Dados Jurisprudencia TRT2. sgjnd@ trtsp.jus.br [mensagem pessoal] [citado 2019 set. 30]. E-mail para Marcia Vieira da Motta (marcia.motta@ gmail.com).

47. São Paulo. Tribunal Regional do Trabalho ( $2^{\mathrm{a}}$ Região). Processo: 0100600-75.2006.5.02.0442. Relator: Maria Inês M. S. A. da Cunha. Santos [processo online]. 2013 jan. 08. [Acesso em 2019 jul. 15]. Diponível em: http:// search.trtsp.jus.br/easysearch/cachedownloader?collecti on $=$ coleta013\&docId=80 cbc6f6dbd9ff018ece $61 \mathrm{~cd} 4 \mathrm{a} 49 \mathrm{ff}$ be $17 f 5730$ c \&fieldName $=$ Documento\&extension $=$ pdf

48. São Paulo. Tribunal Regional do Trabalho ( $2^{\mathrm{a}}$ Região). Processo: 01665.2004.482.02.00-5. Relator: José Roberto Carolino. São Vicente [processo online]. 2010 set. 24. [Acesso em 2019 jul. 15]. Diponível em: http://search. trtsp.jus.br/easysearch/cachedownloader?collection $=$ cole ta013\&docId $=83 \mathrm{c} 10844 \mathrm{~b} 24040 \mathrm{ac} 441 \mathrm{ba} 7 \mathrm{~b} 0 \mathrm{~d} 422 \mathrm{~d} 10 \mathrm{c} 8 \mathrm{c}$ 801551\&fieldName $=$ Documento\&extension $=$ pdf

49. São Paulo. Tribunal Regional do Trabalho (2 $2^{\mathrm{a}}$ Região). Processo: 00554.2005.444.02.00-6. Relator: Davi Furtado Meirelles. Santos [processo online]. 2011 mar. 23. [Acesso em 2019 jul. 15]. Diponível em: http:// search.trtsp.jus.br/easysearch/cachedownloader?collecti on $=$ coleta013\&docId $=7056 \mathrm{~d} 57002514 \mathrm{ab} 09 \mathrm{a} 2 \mathrm{cb} 11 \mathrm{~d} 661$ 5 a5759112aaa2\&fieldName $=$ Documento\&extension $=p d$ $\mathrm{f} \# \mathrm{q}=$

50. São Paulo. Tribunal Regional do Trabalho ( $2^{\mathrm{a}}$ Região). Processo: 0001915.63.2013.5.02.0482. Relator: Eliane Aparecida da Silva Pedroso. São Vicente [processo online]. 2018 mai. 08. [Acesso em 2019 jul. 15]. Diponível em: https://trt-2.jusbrasil.com.br/jurisprude ncia/575196537/19156320135020482-sao-vicente-sp/ inteiro-teor-575196582

51. Paulo. Tribunal Regional do Trabalho ( $2^{\mathrm{a}}$ Região). Processo: 0079200-05.2009.5.02.0020. Relator: Manoel Antonio Ariano. São Paulo [processo online]. 2011 out. 19. [Acesso em 2019 jul. 15]. Diponível em: http:// search.trtsp.jus.br/easysearch/cachedownloader?collecti on $=$ coleta013\&docId=b33458a063170ae29382a5a39df6 $50000 \mathrm{c} 09 \mathrm{e} 3 \mathrm{aa} \&$ fieldName $=$ Documento\&extension $=$ pdf $\# \mathrm{q}=$

52. São Paulo. Tribunal Regional do Trabalho ( $2^{\mathrm{a}}$ Região). Processo: 01837.2004.302.02.00-4. Relator: Rita Maria Silvestre. Guarujá [processo online]. 2008 jan. 29. [Acesso em 2019 jul. 15]. Diponível em: http://search. trtsp.jus.br/easysearch/cachedownloader?collection=cole ta013\&docId $=684 \mathrm{aa} 98 \mathrm{c} 56234 \mathrm{adc} 90 \mathrm{a} 7 \mathrm{bda} 02 \mathrm{acfa} 28 \mathrm{cc} 33$ 0b49d\&fieldName $=$ Documento\&extension $=h t m l \# q=$

53. São Paulo. Tribunal Regional do Trabalho ( $2^{\mathrm{a}}$ Região). Processo: 1001473-27.2016.5.02.0401. Relator: Silvana Abramo Margherito Ariano. Praia Grande [processo online]. 2018 nov. 09. [Acesso em 2019 jul. 15]. Diponível em: http://search.trtsp.jus.br/easysearch/cache downloader? collection $=$ coleta $014 \&$ docId $=$ ed3a2c 93 be 6 01e17de44c6faa14ef2072164efc9\&fieldName=Docume nto\&extension $=\mathrm{html} \mathrm{Hq}$

54. Silva FA. Avaliação epidemiológica das leucemias linfoblásticas em crianas brasileiras e implicações das infecções em sua patogênese [tese] [Internet]. Rio de Janeiro: Instituto Nacional de Câncer; 2009. [Acesso em 2019 jul. 15]. Diponível em: http://bvsms.saude.gov.br/ bvs/publicacoes/inca/Avaliacao_epidemiologica_das leucemias_linfoblasticas_em_(1).pdf

55. Dantas GKS, Silva LTA, Passos XS, Carneiro CC. Diagnóstico diferencial da leucemia linfóide aguda em pacientes infanto-juvenis. Revista da Universidade 
Brandão GR et al. Avaliação do perfil jurisprudencial encontrado no Tribunal Regional do Trabalho da Segunda Região.

Vale do Rio Verde. 2015;13(2):3-18. DOI: http://dx.doi. org/10.5892/ruvrd.v13i1.1877

56. Mendes EA, Teixeira LR, Bonfatti RJ. As condições de saúde dos trabalhadores a partir dos exames periódicos de saúde. Saúde Debate [Internet]. 2017 [Acesso em 2019 jul. 15];41(112):142-54. Disponível em: http://www. scielo.br/scielo.php?script $=$ sci_arttext\&pid=S010311042017000100142\&lng=en. $\quad$ DOI: https://doi. org/10.1590/0103-1104201711212

57. Camboim DC, Figuerôa VMSM, Lima DNO, Abreue-Lima P, Abreu-e-Lima MCC. Carcinoma papilífero de tiroide associado à tireoidite de Hashimoto: frequência e aspectos histopatológicos. J Bras Patol Med Lab [Internet]. 2009 [Acesso em 2019 jul. 15];45(1):75-82. Disponível em: http://www. scielo.br/scielo.php?script=sci_arttext\&pid=S167624442009000100012\&lng=en. DOI: https://doi. org/10.1590/S1676-24442009000100012.

58. Maciel RMB. Carcinoma diferenciado da tiroide (papilífero e folicular): diagnóstico e conduta. Arq Bras Endocrinol Metab [Internet]. 1998 [Acesso em 2019 jul. 15];42(4):299-305. Disponível em: http://www. scielo.br/scielo.php?script=sci_arttext\&pid=S000427301998000400011\&lng=en. DOI: http://dx.doi. org/10.1590/S0004-27301998000400011

59. Wong EY, Ray R, Gao DL, Wernli KJ, Li W, Fitzgibbons $\mathrm{ED}$, et al. Reproductive history, occupational exposures and thyroid cancer risk among women textile workers in Shangai, China. Int Arch Occup Environ Health. 2006;79(3):251-8. DOI: https://doi.org/10.1007/s00420005-0036-9

60. Pagano L, Caputo M, Samà MT, Boldorini GV. Clinicalpathological changes in differentiated thyroid cancer (DTC) over time (2007-2010): data from the University Hospital "Maggiore della Carita" in Novara. Endocrine. 2012;42(2):382-90. DOI: https://doi.org/10.1007/ s12020-012-9612-4

61. Pellegriti G, Frasca F, Regalbuto C, Squatrito S, Vigneri R. Worldwide increasing incidence of thyroid cancer: update on epidemiology and risk factors. J Cancer Epidemiol [Internet].2013 [Acesso em 2019 jul. 15];2013(965212):1-
10. Disponível em: https://www.ncbi.nlm.nih.gov/pmc/ articles/PMC3664492/pdf/JCE2013-965212.pdf. DOI: https://doi.org/10.1155/2013/965212

62. Loureiro G. Rinite ocupacional: Dificuldades no diagnóstico e enquadramento epidemiológico. Rev Port Imunoalergonolia. 2008;16(1):7-27.

63. Venable KM, Chang-Yeung M. Occupational asthma. Lancet. 1997;349(9063):1465-9. DOI: https://doi. org/10.1016/S0140-6736(96)07219-4

64. Fernandes ALG, Stelmach R, Algranti E. Asma Ocupacional. J Bras Pneumol [Internet]. 2006 [Acesso em 2019 jul. 15];32(S1):S27-S34. Disponível em: http://www. scielo.br/scielo.php?script $=$ sci arttext\&pid $=\mathrm{S} 1806$ 37132006000800006\&lng=en. DOI: https://doi. org/10.1590/S1806-37132006000800006

65. Sakano E, Solé D, coordenadores. IV Consenso Brasileiro sobre Rinites 2017 [Internet]. São Paulo: ABORLCCF; 2017. [Acesso em 2019 jul. 15]. Diponível em: https://www.aborlccf.org.br/imageBank/consensoRinite-4-01-11-2017.pdf

66. European Parliament and the Council of the European Union. Regulation (EC) $\mathrm{n}^{\mathrm{o}} 1272 / 2008$, of 16 December 2008. Regulation on classification, labelling and packaging of substances and mixtures, amending and repealing Directives 67/548/EEC and 1999/45/EC, and amending Regulation (EC) No 1907/2006. Official Journal of the European Union. 2008 dec. 31; L353. p. 1-1355.

67. Brasil. Presidência da República, Casa Civil, Subchefia para Assuntos Jurídicos. Decreto-Lei $\mathrm{n}^{\circ}$ 5.452, de $1^{\circ}$ de maio de 1943. Aprova a Consolidação das Leis do Trabalho [Internet]. Brasília, DF; 1943. [Acesso em 2019 jul. 15]. Disponível em: http://www.planalto.gov.br/ ccivil_03/decreto-lei/del5452.htm

68. Brasil. Ministério do Trabalho e Emprego. Secretaria de Segurança e Saúde no Trabalho. Portarina SSST n ${ }^{\circ}$ 3, de 10 de março de 1994. Inclui o benzeno no item "Substâncias Cancerígenas" do Anexo 13 da Norma Regulamentadora - NR-15 da Portaria No 3.214/78. Diário Oficial da União. 2004 mar. 16; Seção 1. p. 3745. 